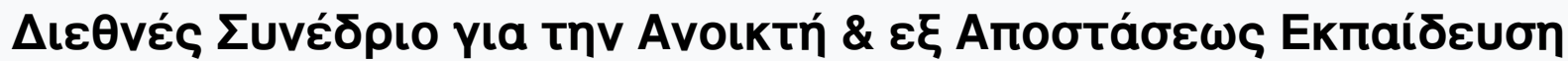

Tón. 8, Ap. 4B (2015)

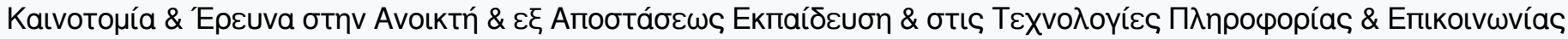

| Пракचiká

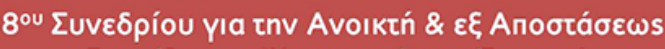

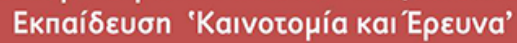

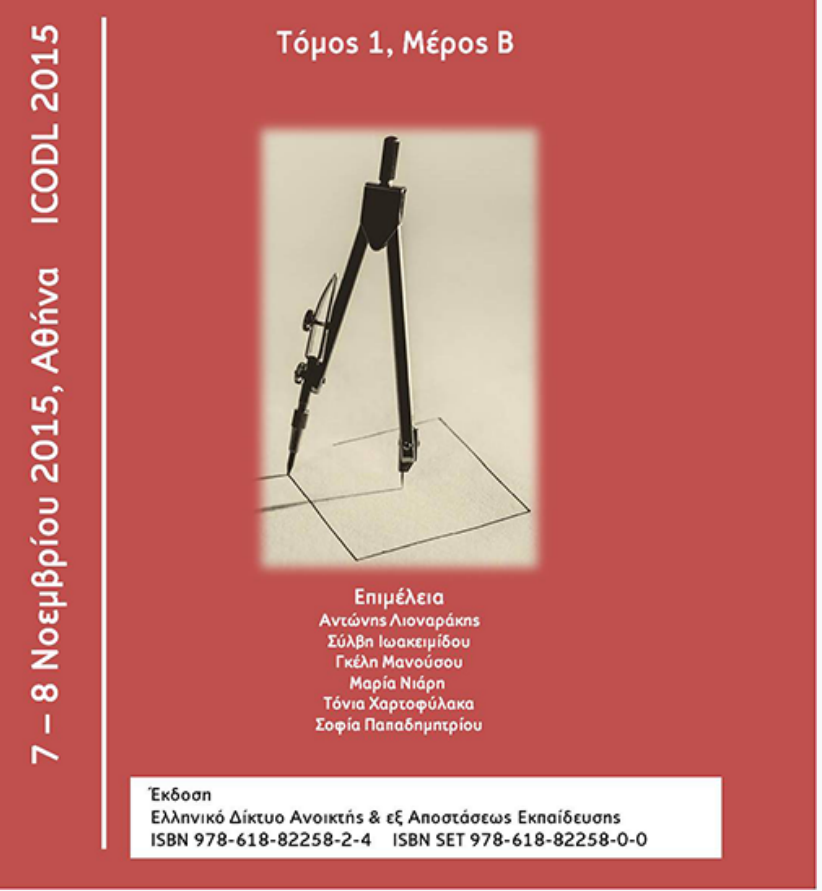

Gamification strategies in learning spaces: A brief toolkit

\section{Raphael Raphael}

doi: $\underline{10.12681 / i c o d l .57}$ 


\title{
Gamification strategies in learning spaces: A brief toolkit
}

\author{
Raphael Raphael, Ph.D \\ American Community Schools (ACS) Athens, Greece \\ Technology Coordinator/Technology Faculty \\ raphaelr@acs.gr
}

\begin{abstract}
What is the role of play in learning? What ways can we as educators leverage our students' extracurricular digital lives in meaningful ways in our digital and physical learning environments? What roles can the elements of game mechanics and game thinking serve towards these ends, especially in a blended learning environment? These are some of the initial questions that guide this brief gamification toolset, a series of practical considerations drawn from field experience and relevant research that may be helpful for teachers and administrators interested in exploring ways to gamify their own digital and physical learning communities or spaces.
\end{abstract}

Key-words: $i^{2}$ Flex, blended learning, gamification, gameful learning

\section{Introduction}

\section{The $i^{2}$ Flex model}

The following paper first provides a brief discussion of common elements of a gamified space followed by a short outline of an intervention done with middle school students during a game programming lab. The paper concludes with a brief set of informal suggestions for teachers and administrators interested in gamifiying a learning environment. The intervention presented was done within an $i^{2}$ Flex model of instruction, a model unique to ACS that has organically developed from the collective practice of faculty. Towards the goal of creating holistic and meaningful learning experiences, the model benefits from research on the blended learning as well as the flipped classroom with an emphasis unique to our learning community and the ACS core vision: guiding students to become 'architects of their own learning.' While the model is intended to be flexible enough to manifest in distinct and inspiring ways depending on the unique learning needs of a particular ACS community, the model shares certain key, overlapping elements: 1. independent/online component- some elements are done by students independently online, often at their own pace; and 2. face-to-face interaction - rich face-to-face learning experiences. These include both (a) guided experiences- in which students may receive in-person guidance on solidifying their understanding or receiving clarification of developing concepts as necessary; and (b) authentic, higher-order learning experiences which give students greater autonomy and choice, often providing students with opportunities to develop their own unique learning goals and objectives. These face-to-face learning experiences are often collaborative in nature or enriched through collaborative elements that may anticipate the kinds of cooperative, problem-solving experiences students are likely to experience in their later professional lives. 


\section{Understanding Gamification: Defined; Use in business}

Before briefly outlining a small portion of my field experience with gamification, it will be useful to outline some of the relevant terminology that provide the framework for the fieldwork. The term gamification has only gained widespread use in the last several years. Broadly speaking, it refers to using game mechanics and game thinking in an environment not usually associated with games to motivate specific behaviors and/or guide users to reach their own goals (Burke, 2014). While the term may still be unfamiliar to some, its widely used in industry. It's estimated that a full $70 \%$ of the world's 2000 largest companies use gamification to structure interaction both with consumers as well as internally, e. g., in the training of their own employees (Khosrow-Pour, 2014). Industry has been so optimistic about the potential of gamification, not only to motivate others but to drive innovation that, in fact, it is estimated that at least half of the globe's largest companies use gamification as their central means of generating innovation (Schawbel, 2013).

\section{Elements of gamification}

Briefly, the following eight typical elements of gamification are drawn from basic game mechanics as well as the elements of contemporary digital game environments:

1. Badges: These are typically used to recognize achievement and/or assignment completion. They are awarded in a digital form, often appearing in a user's profile. They can recognize a desired action, e.g., I awarded a 'community helper' badge for peer tutoring/peer-to-peer learning.

2. Levels: These provide a visible path of actionable steps to mastery and/or task completion. They are generally marked by progressively increasing difficulty, with the last challenge (often called a 'BOSS' challenge) being that of greatest difficulty. A central benefit of using explicit levels is that it may make the entire process, unit, etc. (even if made up of disparate tasks) seem more connected, more meaningful, and more transparent to students.

3. Points: These may be awarded for desired achievement/tasks. Points are valuable in and of themselves; they need not reference anything else, and they may not be connected to actual grades. They only need to be valuable in your game/class world. Some practitioners do tie them to grading (see Lee Sheldon's Multiplayer Classroom for extensive examples of learning spaces that do so [2013].) [note: this element was not used in my interventions.]

4. Missions/Quests - A learning unit or a series of lessons may be grouped as a mission or quest. This aspect is frequently used with the leveling. Some 'missions' may be identified as optional and some as required 'core' missions. These missions may also be tied to social elements of a game, perhaps connected to cooperative group work or 'battles'; these groups may in turn sometime be called 'guilds' or may somehow have a name connected to the particular unit/lesson theme, e.g., 'survival groups' in a gamified solution in an English classroom which presented a gamified Zombie experience for The Great Gatsby (see Gore, 2014).

5. Leaderboard - A snapshot view of top performance. Posted into a digital learning space or displayed in a physical one, these lists of top achievers can be used to motivate performance, encouraging students' competitive instincts. Research suggests that one must be cautious when employing leaderboards, though. It may de-motivate students if they are too far behind the top performers. In comparing their own performance to those at the 'top' of the leaderboard, they may conclude that the gap is impossible to close and simply give up (LevelEleven, n.d.). Leaderboards appear to be best suited for low-stakes activities in which students are all within a similar range of 
ability and/or accomplishment. Its primary reward is providing students with social capital and the resultant boost to self-esteem.

6. Narrative/Story/Lore - one of the most compelling aspects of games is a unified narrative. As order-seeking creatures, we are drawn to satisfying narratives. In a gamified space, these are sometimes framed as 'lore' - the community stories and/or backstories necessary to know to better understand a mission. An effective element of this may be progressive disclosure of the narrative to students. Examples may be as simple as a teacher reading a short imaginative paragraph immediately before a lesson or unit framing it as being part of a magical story or adventure, or as elaborate as framing all activities within a unit as elements of a larger complex story.

7. easter eggs - a traditional programming term referring to purposeless elements left in an environment that are generally only discovered after extensive exploitation. E.g., a teacher might make available an online folder of resources students are assigned to review. Within the folder, a teacher might randomly place a link a short Road Runner and Coyote clip. This may encourage more thorough review of digital materials and help contribute to students' sense of novelty/surprise/variability, e.g., our digital learning space was subscribed to RSS streams of innovative technology news that were not necessary tied to our current class work but instead served as a reward to students for keeping attentive to our Edmodo learning stream (the educational social network used in this research).

8. avatars - The image or icon that represents a user in an (physical and/or digital environment). These are crucial to students' sense of ownership of the digital space. Research suggests individuals can have powerful identification with their avatars that can be leveraged in empowering ways. For example, things that a user sees their avatar do seem more accomplishable in real life. Also, when students have an avatar that has aspects of another identifiable group, research suggests that they may develop more empathy to such groups in real life. For example, a Stanford study by Nick Yee et al. suggests that, remarkably, after young people are given avatars with aspects of the elderly, the students actually measurably demonstrate more compassion towards elderly people in the real world (Yee, 2009). In this light, the fact that Edmodo has a built in avatar-maker that allows one to create an avatar with a mix of elements of different ethnicities and genders is significant.

\section{Intervention: 6th grade: Game design programming lab}

As a touch point, I briefly outline an intervention done with middle school aged students during a series of introductory programming activities culminating in a game design lab. I first outline a few key general assumptions that guide the example project. This is followed by brief mention of learning objective and a general outline of the steps of the project.

\section{Key assumptions}

The rationale for much of this approach is based on certain core assumptions about what encourages student engagement. These are insights drawn from research in project-based learning as well as many of the core assumptions of gamification about what constitutes meaningful student/user engagement. At the core of these assumptions is that students want what all workers crave: meaningful work. This is turn is characterized by several key factors including:

1. choice

2. autonomy 
3. social engagement - chances to work together socially/and have some aspects of competition

4. recognition for achievement

5. a sense of making progress

6. gaining a sense of growing mastery

7. a feeling that all of one's actions fit into some larger purpose

8. the often intangible but essential experience of having fun

\section{Mission [learning objective]}

Students will develop comfort with concepts of computational thinking through programming a simple digital game in the Scratch programming environment. (As part of the students' work, elements of project-based learning were also used in this mission, particularly check ins and checkouts. To keep visual track of their own progress through sequential levels, students also created excel rubrics. Authentic assessment of completed final projects was used as primary means of project assessment.)

\section{Scratch programming - levels/missions}

1. Working independently at their own pace, students complete challenge cards, discrete programming practice skills with particular difficulty level identified. Students could complete in any order, charting their own learning path through the required material on customized, student-build spreadsheets that make their progress at any given time transparent both to the teacher and student.

2. Once students were done with the challenge cards, they received guided introduction to a basic skill set in the Scratch programming environment during faceto-face sessions.

3. This was followed by 'sandbox' exploratory time for students to explore the Scratch interface and develop a list of discoveries and questions about what they wish to learn more about, sharing these discoveries and questions within the class' digital discussion stream.

4. After a face-to-face guided introduction, students moved independently online sequentially through a series of screencasts on game design that I created.

The series of screencasts progress through 5 central lessons to create a basic fully functional game engine including: development of a variable to keep scores; game narrative and setting, including protagonist, enemy, helper substance; and the conditional expressions of a win state and a lose state. This initially guided introduction to programming in face-to-face sessions continues in the independent online component of the course as students complete lessons at their own pace.

5. Face-to-face class sessions were then utilized as programming labs to workshop individual programming or extension issues that students were having, bringing these to whole group class discussions to collectively work out and problem-solve. In a typical session, a student would bring the issue/bug up to the main projector station in the class and the class would together workshop possible solutions. For example, one student's variable might not be working properly or another may have a speculative game idea for which they wished to translate into appropriate scripting, e.g., how do I create an additional variable for a 'life force' for my central character'

6. After completing basic game engine, students then customized their creations to form their own unique games, with presentations during face-to-face sessions showcasing innovative student work. 


\section{Edmodo: Digital environment}

Edmodo was a crucial part of daily class work, serving as a forum for my posting daily agenda, identifying which class aspects were face-to-face, which were guided and which were independent. This included daily digital questions (including metacognitive ones about game use as well as occasional 'check ins' and 'checkouts' [what did you do in the session / what was completed / needs to be returned to]) that gave students practice in articulating their daily objectives as well as self-assessing their daily progress. Edmodo also served as the means by which I awarded progressive badges to students as they progressed through the levels of their game creation project. Perhaps most importantly, the Edmodo course stream also served as an interactive space in which students could also give each other feedback on projects, providing an opportunity for them to have valuable guided practice in digital citizenship as they developed their respectful and purposeful student-led discussions.

\section{Towards a gamification Toolset: Key considerations for gamifying your learning spaces}

The use of gamification strategies within a blended learning environment here illustrated within the $i^{2}$ flex paradigm, appears to offer, at least anecdotally, a series of benefits, including increased student engagement and the possibility of making the learning process and student learning more visible. I close with an informal set of 10 general guidelines that may serve as starting off points of consideration for teachers and administrators interested in exploring gamification strategies within their own digital and physical learning spaces:

\section{Understand the goals of your players/students.}

The key to successful implementation appears to be making sure that your approach aligns with the perceived goals of the students. While there appear to be certain shared needs we all share in our 'work': meaning; social recognition; feeling of making progress towards master; at the same time, these are uniquely reflected in each student, let alone the unique ways they may be expressed in each collective learning environment/community.

2. Be sure to have a compelling theme/suggested narrative (ideally one that is codeveloped with the students)

Narrative is the way that we form meaning as and place together disparate events in a meaningful framework. At a simplest level, this is providing a leveled course map through which the students move. Deeping this, it can be an extended simulation with its own distinct narrative in which students take on identities for the duration of the project. E.g., in another project, my high school students in an introductory computer science course engaged in a simulation in which they formed 'start-up' companies with classmates, branding their companies with student-designed names, logos, mottos, and company websites. These 'start-up' companies were then tasked with securing a 'client' within the school learning community (a teacher, administrator, or student group), and using their skill set acquired in the class to produce a web-based artifact for their client on deadline to the client's specifications.

3. In experimenting with gamifying a learning space, a 'lean education start-up model' may be best. Take advantage of insights from design thinking and in particular the 'lean startup model' which advocates moving forward with the minim viable 'product', i.e., begin with barest functional model to move forward.

4. Closely related to this, iterate, iterate, iterate. 
Enter into your experiment with the understanding that you will be iterating and make changes as necessary. A key part of this is an active feedback loop with students. One of the most compelling elements of digital games is the generally immediate feedback loop they provide the user. As much as possible, attempt to give students opportunity to provide feedback, from simple check ins and check outs each session to give their affective state and self-perception of current project/direction of the class, to short surveys and polls, as well as giving them recognition opportunities through badges, etc. (At the same time, the need for variety and surprise does conversely support the occasional irregular delivery of these.)

5. Closely related to frequent iteration informed by feedback from students, make your experiments with gamifying your learning spaces explicit with the students. This serves at least 3 purposes: (1) it can add to the meaningfulness of their experience as you tell them that their experience and feedback in this process will be very important and will have a significant impact on future iterations of the class, in turn giving them the real potential to impact the lives and learning of many other students. (We frequently overlook the importance of leveraging all opportunities to emphasize potential real-life meaningful aspects of students work); (2) it places students in the esteemed position as experts as they are expected to give their impact and feedback and most importantly lend their extensive knowledge of gaming and digital spaces to your learning community; (3) another benefit may be that the process of rapid prototyping, iterating, and your own enjoyment in the process may serve as a valuable model for professional engagement for students' own later professional life and moreover, invites a reframing of the learning experience as problem-solving apprenticeship.

6. Quality over quantity: the most effective use of gamification is not the one that uses the most gamification elements, but the one that strategically uses what best meets the needs of that particularly learning community and adjusts accordingly to continue to meet that learning community's needs.

7. Keep the insights of project-based learning close to the surface in your work. These include emphasis on real-audience, providing opportunities for student autonomy, and providing students with conscious opportunities to develop their own supporting skill set that is meaningful for their own unique path of mastery.

8. Take a mixed reality approach. Research at Carnegie Mellon suggests that mixing the real and the virtual is most effective (Schaffhauser, 2015). Capitalizing on what is best in a blended approach, be sure to take advantage of opportunities not just to take advantage of the digital environment, but also to add corollary elements into your physical learning environments, e.g., in addition to taking advantage of the use of the course digital environments, (e.g., digital leaderboards, electronic badges and avatars), also utilize elements like physical leaderboards in the physical class spaces in which students' progress is made visible as they physically move their avatars across a series of levels on the display.

9. Create opportunities for fun.

Don't overlook the importance of students' affective experience. The work of Stuart Brown (2010) et al. suggest that, far from being frivolous, a rich play life may be looked at as a key predictor of later emotional, social and cognitive wellbeing.

10. Be sure to fully exploit the social nature of the digital natives' relationship with technology. Far from solely serving as means of isolating and dehumanizing students, as we as teachers sometimes fear, technology (particularly social media) 
appears to offer important realms in which our students are creating more truly democratic communities, participating in, among other things, meaningful peer-topeer tutoring and the validation and recognition of one another's work. While adults (particularly non-digital natives) often lock down or closely monitor student access because of hyper-concern over cyber-bullying and possibilities of online predation, this is often over-emphasized over these potentials. With appropriate scaffolding (ground rules/ clearly defined digital citizenship experiences, etc.), students can blossom. This includes their anticipating (perhaps with a measure of joy) the kinds of blended spaces they are likely to encounter in their later academic and professional lives and helping them feel part of creating truly democratic, participatory digital/physical spaces in which they feel capable and empowered. The hope is this may well invite them to create corollary spaces and experiences in the real world.

\section{References}

Brown, S. L., \& Vaughan, C.C. (2009). Play: How it shapes the brain, opens the imagination, and invigorates the soul. New York: Avery.

Burke, B. (2014). Gamify: How gamification motivates people to do extraordinary things. New York: Bibliomotion.

Gore, B. (2014, October 10). A gory tale of English class. Retrieved October 10, 2015 from: https://gorebobbi.wordpress.com/category/gamification/

Khosrow-Pour, M. (2014). Inventive approaches for technology integration and information resources management. Hershey, PA: Information Science Reference.

LevelEleven. (n.d.) Can sales leaderboards hurt motivation? Available at: http://pages.leveleleven.com/can-sales-leaderboards-hurt-motivation

Schaffhauser, D. (2015, May 11) Research: Young students learn better with mix of virtual and real worlds. THE Journal. Available at: <http://thejournal.com/articles/2015/05/11/young-studentslearn-better-with-mix-of-virtual-and-real-worlds.aspx>

Schawbel, D. (2013, October 7). Adam Penenberg: How gamification is going to change the workplace. Forbes. Retrieved October 15, 2015 from: http://www.forbes.com/sites/danschawbel/2013/10/07/adam-penenberg-how-gamification-isgoing-to-change-the-workplacel

Sheldon, L. (2012). The multiplayer classroom: Designing coursework as a game. Boston: Course Technology/Cengage Learning.

Yee, N., Bailenson, J. N., \& Ducheneaut, N. (2009). The Proteus effect: Implications of transformed digital self-representation on online and offline behavior. Communication Research, 36(2), 285-312. Available at: http://vhil.stanford.edu/pubs/2009/yee-proteus-implications.pdf 